\title{
Os benefícios da oralização e da leitura labial no desempenho de leitura de surdos profundos usuários da Libras
}

\author{
ANDREIA CHAGAS ROCHA TOFFOLO \\ Universidade Federal de Ouro Preto, Ouro Preto, MG, Brasil \\ ELIDÉA LÚCIA ALMEIDA BERNARDINO \\ Universidade Federal de Minas Gerais, Belo Horizonte, MG, Brasil \\ DOUGLAS DE ARAÚJO VILHENA \\ Universidade Federal de Minas Gerais, Belo Horizonte, MG, Brasil \\ ÂNGELA MARIA VIEIRA PINHEIRO \\ Universidade Federal de Minas Gerais, Belo Horizonte, MG, Brasil
}

RESUMO

O aprendizado da leitura da língua portuguesa por surdos tem atraído estudiosos da área em virtude do fraco desempenho nessa habilidade apresentado pela maioria desses indivíduos. Este trabalho tem como objetivo principal averiguar se o uso da leitura labial e/ou da oralização como complemento à Língua Brasileira de Sinais (Libras) pode auxiliar no processo de aprendizagem da leitura do português. Trinta e sete surdos profundos, da comunidade surda brasileira, cursando do $7^{\circ}$ ano do ensino fundamental ao $1^{\circ}$ ano do ensino médio e com idade entre 12 e 18 anos, foram submetidos às Matrizes Progressivas de Raven, a uma entrevista semiestruturada e a dois testes de leitura. Todos os participantes são usuários da Libras, e 57\% a complementam com meios alternativos de comunicação. Nossos dados sugerem que o desenvolvimento de habilidades como a leitura labial e a oralização facilitam o processo de leitura.

PALAVRAS-CHAVE

oralização; leitura labial; educação de surdos; avaliação da leitura de surdos. 


\title{
BENEFITS OF LIP READING AND ORALIZATION IN THE READING PERFORMANCE OF PROFOUND DEAF USERS OF BRAZILIAN SIGN LANGUAGE
}

\begin{abstract}
The learning of reading in Portuguese language by deaf has attracted researchers due to the poor performance in this skill displayed by the vast majority of these individuals. This article aims to investigate whether the use of lip reading and/or oralization, as a complement to the Brazilian Sign Language (Libras), can help literacy in Portuguese. Thirty-seven profoundly deaf students, from the Brazilian deaf community, enrolled from the $7^{\text {th }}$ year of elementary school to the $1^{\text {st }}$ year of high school, aged from 12 to 18 years old, were assessed by Raven Progressive Matrices, a semi-structured interview and two reading tests. All participants are Libras users and 57\% complement it with alternative communication techniques. Our data suggest that the development of lip reading and oralization skills facilitate the reading process.
\end{abstract}

KEYWORDS

oralization; lip reading; deaf education; assessment of the reading of deaf.

\section{LOS BENEFICIOS DE LA LECTURA LABIAL Y DE LA ORALIZACIÓN EN EL DESEMPEÑO DE LA LECTURA DE SORDOS PROFUNDOS USUARIOS DE LA LENGUA BRASILEÑA DE SEÑALES}

\section{RESUMEN}

El aprendizaje de lectura de la lengua portuguesa por sordos atrae estudiosos del área en función del débil desempeño en esa habilidad presentado por la mayoría de esos individuos. Este trabajo tiene como objetivo principal averiguar si el uso de la lectura labial y/o de la oralización como complemento a la Lengua Brasileña de Señales (Libras) puede auxiliar el proceso de aprendizaje de lectura del portugués. Treinta y siete sordos profundos, de la comunidad sorda brasileña, cursando el $7^{\circ}$ año de la educación primaria hasta el primer año del bachillerato y con edades entre 12 y 18 años, fueron sometidos a las Matrices Progresivas de Raven, a una entrevista semiestructurada y a dos pruebas de lectura. Todos los participantes son usuarios de Libras y el $57 \%$ complementa esa lengua con medios alternativos de comunicación. Nuestros datos sugieren que el desarrollo de habilidades como la lectura labial y la oralización facilitan el proceso de lectura.

\section{PALABRAS CLAVE}

oralización; lectura labial; educación de sordos; evaluación de la lectura de sordos. 


\section{INTRODUÇÃO}

A recente Política Nacional de Educação para a população com deficiência auditiva, regulamentada por lei (Brasil, 2002, 2005, 2008), é norteada pelo ensino bilíngue, em que o surdo (não mais referido como "deficiente auditivo") tem o direito de ser educado tanto na Língua Brasileira de Sinais (Libras), como primeira língua (L1), quanto no português escrito, como segunda língua (L2). Tal proposta, que representa um grande avanço na história da educação dos surdos, demanda que o ensino a esse público seja ministrado por professores fluentes em Libras ou traduzido por intérpretes de língua de sinais qualificados.

De forma geral, a proposta bilíngue é bem aceita entre pesquisadores e profissionais da área da educação de surdos. Entretanto, pouco espaço tem sido reservado para a discussão de como essa proposta educacional é concebida na escola - especialmente em relação ao ensino do português como L2. Além disso, o bilinguismo ainda coexiste com outras estratégias de ensino antagônicas, como a abordagem oralista (focada apenas na linguagem oral), os métodos bimodais de ensino (uso da língua de sinais e da oralidade simultaneamente), e ainda a comunicação total (uso de múltiplos recursos, tais como oralidade, leitura orofacial, ${ }^{1}$ gestos, sinais e alfabeto manual) ${ }^{2}$ (Fernandes, 2011; Moura, Campos e Vergamini, 2011).

Embora o aluno surdo tenha o direito de ser educado em Libras como L1 e português escrito como L2, o que se percebe é que esse direito é negado e muitas vezes camuflado por propostas educacionais que se apresentam como bilíngues. Escolas em que os professores ouvintes ministram aulas em português com a mediação de um profissional intérprete, por exemplo, utilizam a língua portuguesa como língua principal de instrução e não a Libras. Nesse caso, o português não é ensinado como L2, o que traz sérias implicações tanto para o aprendizado da língua de sinais quanto da língua portuguesa. É importante destacar que a abordagem pedagógica que as escolas de fato utilizam são difíceis de serem definidas, seja pela dificuldade em obter essas informações das escolas e/ou pelo fato de que em uma mesma instituição é comum que os professores conduzam as aulas com metodologias distintas.

Independentemente das combinações metodológicas utilizadas, uma preocupação atual refere-se ao fato de que a proposta bilíngue não ter conseguido atingir o objetivo de ensinar o surdo a ler o português adequadamente (Botelho, 2010; Silva, 2012). Não dominar a língua majoritária da sociedade na qual se está inserido significa estar alijado da produção de conhecimento. Nesse sentido, pode-se pensar em um risco permanente de vulnerabilidade do surdo, com consequências negativas nos aspectos cognitivos, psíquicos, sociais, políticos e econômicos de sua vida (Soares, 2002). Conforme Masutti (2011, p. 49), "a questão da Língua Portuguesa

1 Leitura orofacial, ou leitura labial, é a habilidade de compreensão da fala por meio de pistas visíveis que acompanham a articulação da fala na face do emissor (Capovilla et al., 2008).

2 O alfabeto manual é um sistema utilizado nas línguas de sinais para representar, por meio das mãos, as letras dos alfabetos das línguas orais escritas (Ferreira-Brito et al., 1997). 
é um ponto nevrálgico na educação de surdos e está intimamente imbricada com o espaço que é dado ou negado à Língua Brasileira de Sinais”.

Tomando as dificuldades de aprendizagem do português como segunda língua, vários fatores podem ser apontados. Por exemplo, no nosso país, cerca de $90 \%$ das crianças surdas nascem em famílias de ouvintes (Brasil, 2007; Moura, Campos e Vergamini, 2011). Privadas da audição, a língua materna não lhes é transmitida de forma natural, como acontece com os ouvintes na aquisição das línguas orais. Além disso, a maioria dos pais ouvintes desconhece a Libras, o que impede que seus filhos a adquiram de forma espontânea em seu ambiente familiar.

Assim, parte significativa dos alunos surdos chega à escola com pouco ou nenhum conhecimento da Libras e/ou da língua portuguesa, ficando a escola responsável por criar condições para que adquiram ambas as línguas. Considerando que o ensino formal do português se inicia por volta dos 6 anos, período em que leitura e escrita normalmente começam a ser trabalhadas com crianças ouvintes nas escolas regulares, conclui-se que, para a maioria das crianças surdas, aprender a ler e a escrever significa aprender a L1 e a L2 ao mesmo tempo (Pereira, 2009).

Além disso, falta aos indivíduos surdos conhecimento de mundo que os auxilie na criação de expectativas e de hipóteses sobre os significados dos textos, e não apenas de vocábulos isolados. Durante a leitura, o leitor é chamado a colaborar preenchendo as lacunas do texto, o que exige que ele tenha uma bagagem cognitiva para a construção da coerência e do sentido textual. Normalmente, as crianças ouvintes chegam à escola com conhecimentos prévios, que incluem histórias passadas por meio das gerações, assim como acontecimentos do dia a dia, regras e valores culturais (Eco, 1984; Kato, 1995; McGuinness, 2006). As crianças surdas, a despeito de também desenvolverem uma bagagem resultante de experiências cotidianas e culturais, não conseguem, como as crianças ouvintes, usufruir da vasta experiência adquirida por meio da linguagem em virtude do atraso no desenvolvimento linguístico. Conforme enfatiza Nader (2011), a aquisição tardia de uma língua restringe não só as interações comunicativas da criança, mas também as possibilidades de aprendizagem de conteúdos (entre os quais os escolares) veiculados pela língua formal (oral ou de sinais), fundamentais para o desenvolvimento cognitivo.

A diferença de modalidades e de níveis linguísticos entre a língua de sinais e uma língua oral é outro empecilho ao aprendizado. A língua de sinais é de modalidade visuoespacial, ao contrário da outra, que é oral-auditiva. Ademais, na língua portuguesa, assim como nas outras línguas alfabéticas, os sons das palavras faladas correspondem, geralmente, aos grafemas na escrita. Conforme enfatiza Quadros (1997a), um grafema, uma sílaba e uma palavra na escrita alfabética não apresentam nenhuma analogia com as unidades de uma língua de sinais. Para aprender a ler, as crianças ouvintes fazem conexões entre a linguagem oral e a escrita, que são códigos relacionados nas escritas alfabéticas (Ehri, 2010; Morton, 1989; Share, 1995). Para as crianças surdas, em especial as com surdez profunda, essa conexão é impossibilitada pela ausência da audição.

Consequentemente, a aprendizagem da leitura e da escrita sempre ocorrerá de maneira não natural para os surdos, visto que, para eles, será sempre em uma segunda língua. Por isso é tão importante que o domínio da língua de sinais como 
L1 aconteça o mais cedo possível, pois, além de favorecer o desenvolvimento do surdo em muitos aspectos (e.g., cognitivo, emocional e social), serve de base para o aprendizado da L2 (Pereira, 2009). Logo, se há atrasos na aquisição da língua de sinais, automaticamente isso se reflete no aprendizado do português.

No entanto, uma vez satisfeito o requisito de "língua de sinais como L1", há ainda desafios a serem superados no que se refere ao ensino da L2 na escola. O principal deles é a falta de compreensão do processamento da leitura na surdez e as estratégias que favorecem a aprendizagem dessa habilidade. Esse conhecimento é necessário para a elaboração de métodos de ensino que se difiram dos utilizados com ouvintes (Capovilla et al., 2005). Outro desafio é romper com a imagem de deficiência linguística muitas vezes atribuída ao surdo, situação na qual o professor tende a subestimar o desempenho do aluno surdo, levando-o a prejuízos educacionais (Silva e Pereira, 2003).

Apesar de todos os fatores listados, felizmente alguns indivíduos surdos conseguem atingir proficiência na leitura. Como isso acontece ainda não está claro para os pesquisadores. No entanto, a partir do trabalho de Mayberry, Giudice e Lieberman (2010), observa-se um salto significativo nas pesquisas sobre os processos de leitura de indivíduos com surdez profunda. Uma importante descoberta nesse novo cenário é a refutação da hipótese de que o fraco desempenho de leitura dos indivíduos surdos seja resultante da falta (completa ou parcial) de um input auditivo, considerado necessário para o desenvolvimento de representações fonológicas bem especificadas. Se essa carência fosse realmente fator preponderante do insucesso na leitura de pessoas com deficiência auditiva, nenhum indivíduo com surdez profunda aprenderia a ler. Isso sugere que o surdo emprega estratégias alternativas no processamento da leitura, diferentes daquelas utilizadas pelos ouvintes.

Ansiando ampliar os recursos disponíveis ao ensino/aprendizagem da leitura para os surdos, alguns pesquisadores têm recorrido a sistemas de comunicação como a leitura labial e a oralidade, brevemente discutidos a seguir. A leitura labial é a observação dos movimentos dos lábios e da boca do interlocutor na tentativa de decodificar a informação que está sendo transmitida. Esse processo nunca é realizado isoladamente, pois é complementado pela observação de pistas, tais como as expressões faciais, os gestos e as mudanças de postura do falante. Conforme Dell'Aringa, Adachi e Dell'Aringa (2007), a leitura labial, de modo geral, é feita inconscientemente e não somente por pessoas com deficiência auditiva, mas também por ouvintes, como uma estratégia para tornar a comunicação mais efetiva.

Sacks (1999) chama atenção para a diferença entre o surdo pré-lingual e o surdo pós-lingual. $\mathrm{O}$ surdo pré-lingual não tem nenhuma experiência auditiva e, por isso, é incapaz de saber o que é o som. Para ele, a leitura labial é uma experiência inteiramente visual, uma vez que se vê o movimento dos lábios, mas não se ouve a voz - nem sequer se conhece o que ela é. De forma poética, o autor diz que "ele [o surdo] não ouve, ele vê a 'voz' das palavras" (Sacks, 1999, p. 20).

Contudo, é importante frisar que a realização de uma comunicação de qualidade por meio da leitura labial é extremamente difícil, uma vez que ela não é uma habilidade apenas visual. Estima-se que 75\% dela seja uma espécie de adivinhação, de conclusão por hipóteses, que vai depender do uso de pistas encontradas no contexto, 
como a articulação do locutor, a proximidade ou distância dele, a importância da perspectiva frontal dos lábios do falante em relação ao surdo, a semelhança articulatória de determinados fonemas e o prévio conhecimento das palavras pronunciadas (Sacks, 1999; Svartholm, 2011; Witkoski, 2009).

De forma distinta, a oralidade diz respeito à habilidade da pessoa surda de se expressar oralmente, o que ocorre por meio do aprendizado da articulação das palavras e das distinções físicas entre os movimentos articulatórios labiais. Normalmente, tal habilidade é desenvolvida por meio de sessões fonoaudiológicas, prática de leitura labial e uso de próteses auditivas, o que possibilita maior autonomia de comunicação com as pessoas ouvintes.

É importante frisar que não estamos nos referindo a práticas educacionais que tiveram início no século XVI e que visavam à "recuperação" dos surdos por meio do ensino da fala e da proibição dos sinais. Ser oralizado era um requisito para que o surdo fosse aceito socialmente, o que deixava a imensa maioria dos surdos de fora de toda possibilidade educativa, do desenvolvimento pessoal e da integração na sociedade (Lacerda, 1998). Em virtude do fracasso em oferecer condições efetivas para a educação e o desenvolvimento da pessoa surda, o oralismo passou a ser altamente criticado, dando espaço a novas propostas, como a educação bilíngue, que prevê uma relação harmoniosa entre a língua de sinais e a língua portuguesa.

Enquanto alguns autores defendem o ensino da leitura labial, outros defendem o ensino da oralidade, com ambos sendo auxiliados por outros recursos. Considerando a primeira posição, para Leybaert (2005), por exemplo, a leitura labial e a Linguagem Falada Completada (LFC) devem ser estimuladas. A LFC, chamada em inglês de Cued Speech, trabalha com a língua de sinais para complementar e resolver as ambiguidades inerentes à leitura labial.É um sistema baseado em fonemas, que faz com que a língua falada torne-se acessível por meio de um pequeno conjunto de configurações de mão (representando consoantes) em diferentes posições próximas à boca (representando vogais), que funciona como um complemento à leitura labial. A LFC possibilita maior percepção dos fonemas, uma vez que, como muitos deles são iguais no tocante ao modo e ao lugar de articulação (e.g., $/ \mathrm{p} / \mathrm{e} / \mathrm{b} /)$, os sinais manuais introduzem um contraste visual em vez do contraste acústico com o qual os ouvintes estão acostumados (Alegría et al., 1990; Cornett e Daisey, 1992; Leybaert, 2005). Já para Capovilla e Capovilla (2002), a pessoa com surdez que é oralizada (ou seja, que consegue articular a fala) é capaz de ler e escrever com maior correção e fluência que aquela que utiliza apenas a língua de sinais. Como parte dos fonemas não possui representação acústica independente, a informação visual da fala, perceptível na face do emissor, somada aos grafemas da escrita, oferece informação suplementar de grande valia para o alfabetizando surdo aprender as relações existentes entre escrita e fala (Capovilla et al., 2008; Morais, 1996).

3 Os sinais são formados a partir da combinação do movimento das mãos com determinado formato em determinado lugar, podendo esse lugar ser uma parte do corpo ou um espaço em frente ao corpo. Essas articulações das mãos são chamadas de parâmetros. A configuração das mãos é um dos parâmetros da língua de sinais, que se refere às formas das mãos durante a sinalização (Ferreira-Brito et al., 1997). 
As sugestões desses autores coincidem com a observação de professores que relatam que as crianças surdas que fazem uso de meios de comunicação alternativos além da língua de sinais, normalmente, destacam-se na leitura em relação às que utilizam somente a última modalidade. É possível que o emprego dessas formas alternativas funcione como uma maneira de compensar a limitação auditiva.

Com base nessas informações, este trabalho, tomando uma amostra de indivíduos com surdez profunda, objetiva testar o efeito da utilização de comunicações alternativas como complemento à Libras no desempenho da leitura. Mais especificamente, irá averiguar:

1. se os surdos que fazem o uso da Libras concomitantemente à leitura labial e/ou à oralização obtêm melhores resultados em testes de leitura quando comparados aos seus pares que somente utilizam Libras,

2. a relação da idade de aquisição da Libras com o desempenho em leitura e

3. a influência da inteligência não verbal na leitura de surdos profundos.

A relevância de investigações sobre o tema está na urgência de resultados que possam gerar recomendações sobre como melhor ensinar pessoas com surdez para que se tornem leitores hábeis e possam participar ativamente da cultura majoritária de seu país, onde a língua portuguesa é uma das principais pontes para o mundo dos ouvintes.

\section{MÉTODO}

\section{AMOSTRA}

Trinta e sete alunos da comunidade surda brasileira, cursando do $7^{\circ}$ ano do ensino fundamental ao $1^{\mathrm{o}}$ ano do ensino médio participaram da pesquisa. Todos os participantes possuem surdez profunda e são filhos de pais ouvintes. Possuem idade entre 12 e 18 anos $(M=15,5 ; D P=1,7)$, sendo $59,5 \%$ do sexo masculino (Tabela 1$)$.

Tabela 1 - Frequência da amostra de acordo com a idade, sexo e ano escolar

\begin{tabular}{l|c|c|c|c|c|c|c}
\hline \multirow{2}{*}{ Idade } & \multicolumn{3}{|c|}{ Sexo } & \multicolumn{3}{c|}{ Ano Escolar } & \multirow{2}{*}{ Total } \\
\cline { 2 - 8 } & Masculino & Feminino & $7^{\mathbf{0}}$ & $8^{\mathbf{0}}$ & $9^{\mathbf{0}}$ & $1^{\mathbf{0}}$ & \\
\hline 12 & 1 & 1 & 2 & & & & 2 \\
\hline 13 & & 2 & 2 & & & & 2 \\
\hline 14 & 4 & 4 & 6 & 2 & & & 8 \\
\hline 15 & 3 & 1 & 1 & & 2 & 1 & 4 \\
\hline 16 & 7 & 5 & & 8 & 2 & 2 & 12 \\
\hline 18 & 2 & 2 & 1 & 2 & & 1 & 4 \\
\hline Total & 22 & 14 & 12 & 15 & 6 & 4 & 37 \\
\hline
\end{tabular}

Fonte: banco de dados da pesquisa.

Elaboração dos autores. 
Para fins práticos e metodológicos, a amostra foi organizada em dois grupos: G1 usuários somente da Libras; G2 - possuem pelo menos um meio de comunicação além da Libras.

Nenhum participante possui implante coclear e, embora muitos não soubessem especificar o grau exato de sua perda auditiva, confirmaram se encaixar nos critérios de inclusão da presente pesquisa (surdez profunda). A escolha desse grau de perda auditiva deve-se à tentativa de se ter uma amostra homogênea no que se refere à audição, minimizando a possibilidade de interferência de diferentes resíduos auditivos no desempenho das tarefas de leitura.

Em virtude da escassez de escolas especializadas para o ensino de alunos surdos em Belo Horizonte que se enquadrasse dentro do perfil escolar investigado, foi necessário incluir no estudo participantes de instituições de outras cidades. Dessa forma, a amostra foi coletada em quatro instituições de cidades de grande porte em três estados brasileiros, assim distribuídos: uma em São Paulo, duas no Paraná e uma em Minas Gerais (por razões éticas, as escolas serão representadas por números, e as regiões em que se encontram em cada cidade não serão especificadas para evitar a sua identificação). O Quadro 1 apresenta o número de alunos testados em cada escola, assim como a sua caracterização de acordo com o tipo de ensino ministrado. A Escola 1, instituição de ensino bilíngue para surdos (Libras como L1 e português escrito como L2), conta com professores fluentes em Libras e que não necessitam de auxílio de um profissional intérprete. Duas escolas (Escola 2 e 3) são regulares inclusivas e também trabalham com ensino bilíngue, com os professores ministrando suas aulas em português com a tradução de um profissional intérprete de Libras. Apenas a Escola 4 utiliza a abordagem oralista, sem a necessidade de intérprete em sala — consequentemente, não apresenta alunos que utilizam apenas a Libras como meio de comunicação.

\section{INSTRUMENTOS}

Para a avaliação dos participantes foram utilizadas as Matrizes Progressivas de Raven (RPM), uma entrevista semiestruturada, o Teste de Competência de Leitura de Palavras (TCLP) e o Teste de Competência de Leitura de Sentenças (TCLS). Todas as análises estatísticas foram realizadas pelo software IBM SPSS Statistics versão 21.0 (IBM, 2012). Para encontrar valores discrepantes, ou seja, que tenham saído da curva de normalidade, foi utilizada a técnica Outliers Labeling

Quadro 1 - Caracterização das instituições de ensino

\begin{tabular}{|l|c|c|}
\hline Escola & $\mathrm{n}$ & Tipo de ensino \\
\hline 1 & 12 & Ensino bilíngue, sem intérprete \\
\hline 2 & 6 & Ensino bilíngue, com intérprete \\
\hline 3 & 12 & Ensino bilíngue, com intérprete \\
\hline 4 & 7 & Ensino oralista, sem intérprete \\
\hline
\end{tabular}

Fonte: banco de dados da pesquisa.

Elaboração dos autores. 
Rule com o valor rigoroso de 2.2 para o $g$ (Hoaglin e Iglewicz, 1987; Tukey, 1977). Dessa forma, no G1, houve valores discrepantes no escore bruto das RPM $(n=1)$ e no escore ponderado do TCLS $(n=1)$. Já no G2 foi encontrado outliers nos escores ponderados do TCLS $(n=2)$ e do TCLP $(n=1)$. Esses valores sofreram o processo de winsorizing (Wilcox, 2010), sendo arredondados para o valor mais próximo, não excluindo nenhum dado da amostra.

\section{Matrizes Progressivas de Raven (RPM) - escala geral}

As RPM são uma rápida estimativa do componente não verbal do fator $g$ de Spearman, que representa a atividade intelectual global do sujeito (Raven, 2011). O teste é composto de 60 desenhos incompletos (divididos em cinco séries com dificuldade crescente), cujo objetivo é selecionar apenas uma das seis ou oito opções de resposta dispostas logo abaixo (Raven, 2008). Essa avaliação cognitiva já sofreu validação concorrente e preditiva com uma população de surdos de 10 a 19 anos (Blennerhassett, Strohmeier e Hibbett, 1994). Esse mesmo estudo de validação demonstrou que houve correlação entre o resultado das RPM com as avaliações da linguagem, justificando assim o uso da capacidade intelectual, no presente estudo, como covariável. As aplicações foram realizadas por psicólogas, que conferiram todas as folhas de respostas quanto à discrepância nos resultados, levando à exclusão de apenas um sujeito de todas as análises. Todos os outros sujeitos da amostra apresentaram discrepância zero, demonstrando boa consistência interna, assegurando a confiabilidade da coleta de dados.

\section{Entrevista semiestruturada}

A entrevista foi feita com base em um questionário elaborado para rastrear o modo de comunicação do aluno e sua história em relação à surdez. O instrumento, construído pela primeira autora desta pesquisa, é composto de cinco categorias de perguntas fechadas que abordam dados pessoais, tipo de surdez, comunicação e escolaridade do participante. Buscou-se levantar quais os meios de comunicação (Libras, oralidade e/ou leitura labial) eram utilizados, desde a infância, nos ambientes familiar, social, profissional e escolar. No estudo de Bélanger, Baum e Mayberry (2012), a habilidade de entender a fala por meio de leitura labial em diferentes contextos (na escola/trabalho, no ambiente familiar, com amigos, nas lojas/restaurantes e com estranhos) foi medida por uma escala de 0 a 7 . No entanto, desconhecemos instrumentos para medir a leitura labial no português brasileiro. As entrevistas foram realizadas individualmente, em língua de sinais (Escolas 1, 2 e 3) e oralmente (Escola 4). Nas Escolas 1 e 2, as entrevistas foram conduzidas pela primeira autora da pesquisa e, nas Escolas 3 e 4, pela própria professora dos alunos. Após sua realização, foram transcritas para o português pelas aplicadoras, profissionais proficientes em Libras.

Teste de Competência de Leitura de Palavras - TCLP 1.1

O TCLP, desenvolvido e normatizado por Capovilla et al. (2004) para pessoas surdas cursando do $2^{\circ}$ ao $9^{\circ}$ ano do ensino fundamental, avalia a competência da 
leitura silenciosa de palavras isoladas por meio do controle de diferentes variáveis psicolinguísticas. Segundo seus autores, o instrumento é um recurso auxiliar no diagnóstico diferencial dos distúrbios de aprendizagem da leitura. Por meio dele é possível inferir o grau de desenvolvimento e preservação das estratégias logográfica, alfabética e ortográfica.

O teste é composto de setenta itens agrupados em sete categorias de palavras e pseudopalavras que devem ser associadas, do ponto de vista ortográfico e semântico, à figura correspondente (Figura 1). A tarefa do participante consiste em circundar os itens corretos e marcar um " $\mathrm{X}$ " nos incorretos. Os pares palavra-figura, compostos de palavras corretas regulares e irregulares, devem ser aceitos. Já os pares com incorreção semântica ou pseudopalavras devem ser rejeitados. Os erros denotam o tipo de leitura utilizada e mostram possíveis falhas no processo de aprendizagem da habilidade testada pelo item.

As análises utilizaram o escore bruto e o ponderado. Ou seja, considerando a pontuação bruta máxima de setenta pontos, os alunos do $7^{\circ}$ ano do ensino fundamental podem obter escore ponderado máximo de 120,41 , os do $8^{\circ}$ ano, 116,14 e os do $9^{\circ}$ ano, 113,95. Em virtude da inexistência de normatização para os alunos do $1^{\circ}$ ano do ensino médio, esse grupo $(n=4)$ foi enquadrado na categoria do $9^{\circ}$ ano do ensino fundamental.

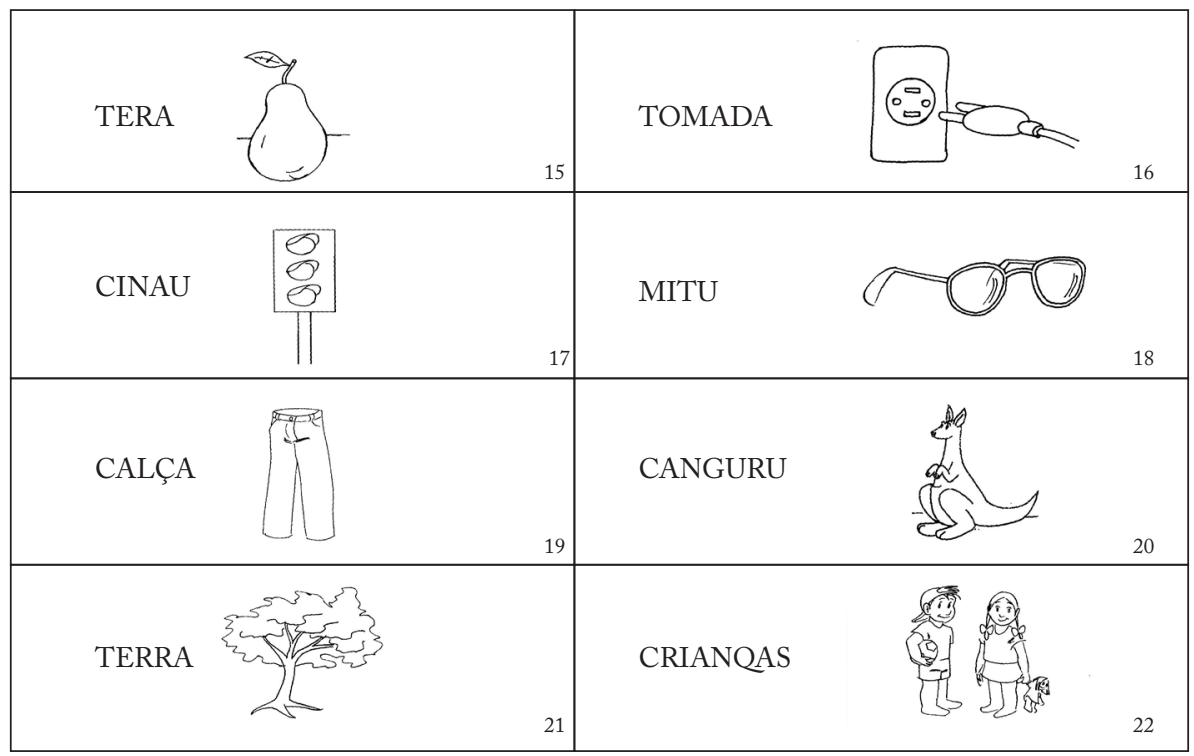

Figura 1 - Exemplos de cada um dos sete tipos de pares de figura e escrita da versão original do Teste de Competência de Leitura de Palavras (TCLP1.1)

Nota: na figura temos: duas palavras corretas, uma regular (TOMADA) e uma irregular (CALÇA), uma palavra com incorreção semântica (TERRA sob figura de árvore), uma pseudopalavra com troca visual (TERA) e uma com troca fonológica (CANCURU), uma pseudopalavra homófona (CINAU) e duas pseudopalavras estranhas (CRIANQAS e MITU).

Fonte: Capovilla et al. (2004, p. 656). 
Teste de Competência de Leitura de Sentenças - TCLS 1.1

O TCLS avalia a compreensão de leitura de sentenças por surdos, sendo desenvolvido e normatizado por Capovilla et al. (2005). O teste consiste em um caderno com cinco itens de treino mais quarenta itens de teste, em que cada um é formado por uma sentença escrita em português seguida de cinco figuras alternativas para escolha (Figura 2). A tarefa do examinando consiste em ler a sentença e escolher a figura que melhor corresponde a ela. Entre as cinco figuras alternativas, apenas uma é correta, sendo as outras quatro distratoras, podendo referir-se a palavras isoladas ou a segmentos menores da sentença, com o propósito de induzir erros decorrentes de extração incompleta do significado, o que permite a detecção de falhas no processamento sintático. No decorrer do teste, as sentenças aumentam em sua extensão, complexidade sintática e lexical e em suas relações de correspondência com as figuras das alternativas de escolha. A habilidade de extração de significado demanda uma série de outras habilidades, entre as quais se destacam: decodificação e reconhecimento de palavras, vocabulário, memória de trabalho e competência sintática em português. No presente estudo, as análises estatísticas avaliaram o escore bruto e o ponderado. Considerando um escore bruto máximo de quarenta pontos, os alunos do $7^{\circ}$ ano do ensino fundamental obtêm escore ponderado máximo de 127,90 , os do $8^{\circ}$ ano, 119,84 e os do $9^{\circ}$ ano, 119,56. Assim como no TCLP, o TCLS não apresenta normatização para os alunos do $1^{\circ}$ ano do ensino médio, o que nos levou a enquadrá-los no $9^{\circ}$ ano do ensino fundamental.

\section{RESULTADOS}

\section{ANÁLISE DESCRITIVA DA ENTREVISTA SEMIESTRUTURADA}

Verificou-se que 26 alunos (70\%), demarcados em sublinhado na Tabela 1, estão com seu ano escolar defasado em relação à sua idade cronológica. Ou seja, estão além de uma margem de 2 anos da idade certa (e.g., para o $7^{\circ}$ ano, é esperado que os alunos estejam entre 11 e 13 anos). Entre esses alunos fora do devido ano escolar, 8 (22\%) apresentam uma defasagem de 3 anos ou mais.

$\mathrm{Da}$ amostra, $27 \%$ só tiveram o primeiro contato com a Libras entre 2 e 4 anos, $32 \%$ entre 5 e 7 anos, $14 \%$ entre 8 e 10 anos e $27 \%$ entre 11 e 16 anos. Apenas $8 \%$ dos alunos disseram se comunicar com seus pais em língua de sinais, e outros $20 \%$ somente a utilizam parcialmente. Os demais (72\%) relatam utilizar de

$\mathrm{E}$ O homem está no barbeiro fazendo a barba porque não tem gilete nem barbeador

Figura 2 - Exemplo do item E de treino do Teste de Competência de Leitura de Sentenças (TCLS 1.1) Fonte: Capovilla et al. $(2005$, p. 816$)$. 
forma precária múltiplos recursos para se comunicarem com seus familiares, como gestos, escrita, leitura labial e oralidade.

Como se pode verificar na Tabela 2, todos os participantes sabem se comunicar por meio da Libras, com $43 \%$ utilizando a oralidade e $46 \%$ fazendo uso da leitura labial. Entre toda a amostra, 16 alunos (43\%) se comunicam apenas por meio da Libras, não sabendo se expressar pela comunicação oral ou leitura labial. Os outros 21 sujeitos (57\%) sabem se comunicar, além do uso da Libras, por meio da oralidade e/ou da leitura labial. A fluência na língua de sinais foi observada durante a entrevista (e também em todo o processo de aplicação dos instrumentos) em que as interações ocorriam por meio da Libras.

\section{AVALIAÇÃO COGNITIVA}

A Análise de Covariância (ANCOVA) (covariáveis: ano escolar, idade, sexo e escola) mostrou não haver diferença significativa no escore bruto nem no percentil das RPM entre o G1 e G2, o que significa que os dois grupos não se diferem em capacidade cognitiva. Como se pode ver na Tabela 3 , os grupos apresentaram médias muito semelhantes nas RPM.

Os participantes $(N=37)$ obtiveram uma amplitude do escore bruto de 20 a 46 , com média de $36(D P=8)$. Esse valor está de acordo com o encontrado em estudos das RPM para a população com surdez: $34(D P=11)$ e $35(D P=8)$ (Blennerhassett, Strohmeier e Hibbett, 1994; Neves e Alarcão, 2012; respectivamente).

Quando consideramos o percentil, encontramos um valor mínimo de 8 e máximo de $63(M=35 ; D P=18)$, sem nenhum participante ultrapassando a categoria de inteligência mediana. De fato, $41 \%$ da amostra apresentou percentil abaixo de 25 pontos. No entanto, uma vez que esses valores encontram-se

Tabela 2 - Frequência de alunos de acordo com a comunicação

\begin{tabular}{l|c|c}
\hline Comunicação & $\mathrm{n}$ & $\%$ \\
\hline Libras & 37 & 100 \\
\hline Oralização & 16 & 43 \\
\hline Leitura labial (LB) & 17 & 46 \\
\hline G1 = Apenas Libras & $\mathbf{1 6}$ & $\mathbf{4 3}$ \\
\hline Apenas oralidade & 0 & 0 \\
\hline Apenas LB & 0 & 0 \\
\hline Libras + Oralidade & 4 & 11 \\
\hline Libras + LB & 5 & 14 \\
\hline Libras + Oralidade + LB & 12 & 32 \\
\hline G2 = Libras + Oralidade e/ou LB* & 21 & 57 \\
\hline
\end{tabular}

* Não houve diferença estatísticas nos testes de leitura e nas RPM entre o grupo dos que sabem Libras e somente oralidade $(n=4)$; o dos que sabem Libras e somente leitura labial $(n=5)$; e o dos que sabem Libras, oralidade e leitura labial $(n=12)$. Esses três grupos foram aglomerados para formar o G2.

Fonte: banco de dados da pesquisa.

Elaboração dos autores. 
igualmente distribuídos entre o G1 e o G2, não foi necessário excluir nenhum sujeito da amostra.

\section{AVALIAÇÃO DA LEITURA}

Para demonstrar a confiabilidade dos testes de leitura, foi realizada uma análise de correlação bivariável de Pearson com bootstrap baseado em mil amostras, apresentada na Tabela 4. Como esperado, o escore bruto do TCLP apresentou uma correlação forte com o escore bruto do TCLS $(r=.72 ; p=.000001 ; N=37)$. Capovilla et al. (2005) obtiveram valores próximos aos encontrados na atual pesquisa $(r=.64 ; p<.0001 ; N=492)$. Utilizando a mesma técnica anterior, não foi encontrada correlação entre os escores brutos do TCLP e os das RPM. No entanto, tal relação com as RPM, apesar de fraca, foi encontrada com os resultados do TCLS $(r=.36 ; p=.03)$, o que justifica a utilização das RPM como covariável em algumas das análises.

Em todas as seguintes análises, utilizou-se o teste de Levene para verificar a igualdade de variância na amostra (variância da homogeneidade). Tanto o TCLP quanto o TCLS apresentaram o valor $p$ mínimo de 6 e .4, respectivamente, aumentando a confiabilidade dos resultados, pois reduz o erro Tipo I e Tipo II ao analisar a hipótese nula (Martin e Bridgmon, 2012).

Para a primeira análise, a de desempenho linguístico, foi realizada uma Análise Multivariada de Covariância (MANCOVA), tendo como variável dependente a combinação dos escores ponderados dos testes de leitura (o TCLP e TCLS foram tratados como uma única medida); tendo como variável independente o meio de

Tabela 3 - Médias (Erro padrão) das Matrizes Progressivas de Raven e dos escores ponderados dos testes de leitura

\begin{tabular}{l|c|c|c|c}
\hline \multirow{2}{*}{} & \multicolumn{2}{|c|}{ RPM } & \multicolumn{2}{c}{ Avaliação da leitura } \\
\cline { 2 - 5 } & Bruto & Ponderado & TCLP & TCLS \\
\hline Geral & $36(1.2)$ & $34(3)$ & $97(2)$ & $97(2)$ \\
\hline Grupo 1 & $36(2.0)$ & $35(5)$ & $89(2)^{*}$ & $90(3)^{*}$ \\
\hline Grupo 2 & $36(1.7)$ & $34(4)$ & $103(2)$ & $102(3)$ \\
\hline
\end{tabular}

Valores ajustados com MANCOVA: ${ }^{*} p<.001$

Fonte: banco de dados da pesquisa.

Elaboração dos autores.

Tabela 4 - Correlação de Pearson entre os valores brutos das avaliações de leitura e da inteligência geral

\begin{tabular}{l|c|c}
\hline & TCLS & RPM \\
\hline TCLP & $0,72^{* *}$ & 0,24 \\
\hline TCLS & 1 & $0,36^{\circ}$ \\
\hline
\end{tabular}

Correlação significativa ao nível de *.05 e **.01 (2 extremidades).

Fonte: banco de dados da pesquisa.

Elaboração dos autores. 
comunicação; e covariáveis sendo o escore bruto nas RPM, o sexo, o ano escolar, a idade e a instituição de ensino. Os alunos do $\mathrm{G} 1$ obtiveram desempenho de leitura inferior aos do G2 [Traço de Pillai: $F_{(2,29)}=9,6 ; p=.001$ ]. Essa análise é robusta, pois agrega ambos os testes de leitura em uma mesma medida de capacidade linguística, além de considerar fatores sociodemográficos e desenvolvimentais que podem influenciar os resultados.

Posteriormente foi realizada uma análise com os mesmos parâmetros que a análise anterior, porém utilizando como variável dependente os testes de leitura separadamente. Como demonstrado na Tabela 4, constatou-se, com resultados corrigidos pelo critério de Bonferroni, que o $\mathrm{G} 1$ obteve desempenho inferior ao G2 tanto no TCLP $\left[F_{(1,30)}=18 ; p=.0002\right]$ quanto no TCLS $\left[F_{(1,30)}=7,8 ; p=.009\right]$, mesmo quando controlado por cinco covariáveis.

Por fim, foi averiguado se havia uma correlação entre o desempenho nos testes de leitura com a idade em que o aluno teve o primeiro contato com a Libras. Por meio de uma análise bivariável, não foi evidenciada nenhuma correlação entre a pontuação no TCLP, TCLS ou nas RPM com a idade em que o aluno teve o primeiro contato com a Libras. Tal resultado pode ter sido ocasionado pela falta de precisão do relato dos entrevistados quanto à idade em que aprenderam a Libras, além do fato de que todos os surdos da amostra tiveram contato com a Libras muito tardiamente, mesmo considerando que $27 \%$ deles tiveram dos 2 aos 4 anos, o que é menos grave, mas ainda muito tarde em comparação com as crianças ouvintes, que começam a escutar no ambiente intrauterino (e.g., Lindner, 1999).

\section{DISCUSSÃO}

Todos os participantes do estudo utilizam a Libras, o que é desejável, já que é consenso que a língua de sinais, por suas características visuoespaciais, constitui a modalidade ideal para a aquisição de L1 pelo surdo. De fato, os estágios da aquisição da língua de sinais por surdos podem ser comparados aos da aquisição da língua oral por ouvintes, desde que eles estejam imersos em ambiente linguístico que propicie essa aquisição (Quadros, 1997b). Logo, a língua de sinais pode oferecer aos surdos todas as possibilidades cognitivas proporcionadas pela linguagem oral nos ouvintes.

No entanto a utilização de uma língua de sinais como único meio de comunicação não é suficiente para o estabelecimento de interações entre surdos e ouvintes. Visando diminuir essa limitação, muitas pessoas surdas acabam recorrendo a formas alternativas de comunicação. Em nossa amostra, 57\% dos participantes utilizam leitura labial e/ou oralidade, que são formas de comunicação com a comunidade ouvinte. Diante dos benefícios obtidos na ampliação das interações sociais do surdo para além de seus pares, o que é proporcionado pela utilização desses meios alternativos de comunicação, o presente trabalho, com foco na aprendizagem da leitura pelo surdo, buscou investigar se a leitura labial e/ou a oralidade combinadas com a Libras são também benéficas para a aquisição da L2 pelos surdos, como atestado por muitos professores.

Dessa forma, a pergunta central do trabalho é: "A utilização de uma língua de sinais (no caso a Libras) em combinação com meios alternativos de comunica- 
ção facilita a aprendizagem da leitura em uma escrita alfabética (no caso, a língua portuguesa) por surdos?"

Os dados encontrados sugerem que a combinação da Libras com a leitura labial e/ou a oralização é um agente facilitador da aprendizagem da leitura em indivíduos com surdez profunda. Como demonstrado, o grupo de leitores que utiliza apenas a Libras (G1) obteve desempenho inferior ao grupo que utiliza a Libras associada a outros meios de comunicação (G2) em ambas as provas de leitura (TCLP e TCLS), mesmo quando controladas características sociodemográficas e desenvolvimentais.

Tal achado parece evidenciar que a leitura pode ser beneficiada quando o sujeito possui um arcabouço de comunicação ampliado, o que supomos lhe conferir maior flexibilidade cognitiva por processar a informação linguística de forma multissensorial. Além disso, a leitura labial e a oralização de nossos participantes podem tê-los aproximado da língua portuguesa, uma vez que esta se relaciona mais com a língua oral que com a Libras.

No entanto, em relação à leitura labial, a conclusão de que esse meio alternativo de comunicação em combinação com a Libras favorece a leitura deve ser tomada com cautela em razão dos achados da literatura. Bélanger, Baum e Mayberry (2012), por exemplo, em um estudo experimental bem conduzido, mostraram que as habilidades de compreensão da fala por meio de leitura labial em uma amostra de surdos profundos classificados como leitores hábeis e menos hábeis não previram o nível de leitura dos participantes. Esse achado está de acordo com os autores supracitados (Sacks, 1999; Svartholm, 2011), que consideram a comunicação por meio da leitura labial limitada e imprecisa. No entanto, vale ressaltar que todos os estudos citados foram conduzidos em outros idiomas.

O estudo de Bélanger, Baum e Mayberry (2012) teve como participantes surdos que faziam leitura labial do francês, que, como o inglês, é uma das línguas mais irregulares no que se refere à correspondência grafema-fonema. A respeito do inglês, somente cerca de $30 \%$ dos sons são visíveis nos lábios, e $50 \%$ das palavras são homófonas, ou seja, possuem a mesma articulação de outras palavras. As articulações labiais das palavras "kite", "height" e "night" apresentam quase nenhuma diferença entre si. Já "maybe", "baby" e "pay me" apresentam o mesmo movimento labial.

É possível que haja maior regularidade articulatória no caso do português brasileiro em comparação a idiomas tais como o francês e o inglês, o que faz com que a leitura labial seja mais precisa. Essa, no entanto, é apenas uma hipótese, já que não encontramos nenhum trabalho que a comprove.

\section{IDADE DE AQUISIÇÃO DA LIBRAS E DESEMPENHO EM LEITURA}

Nenhum surdo da amostra teve contato com a Libras antes dos 2 anos. Assim, $61 \%$ dos pesquisados tiveram o primeiro contato com a língua de sinais entre 2 e 7 anos, e o restante (39\%) somente após os 8 anos, o que significa que grande parte de nossos participantes chegaram ao ensino fundamental sem o domínio da língua de sinais. Essa aquisição tardia da L1 pode ter influenciado a defasagem do ano escolar com relação à idade cronológica de $70 \%$ da amostra. 
As teorias sobre o desenvolvimento da linguagem são consistentes em afirmar que as crianças privadas de interações linguísticas de qualidade (sejam elas na forma de sinais ou na modalidade auditiva) têm o desenvolvimento seriamente comprometido e podem nunca se recuperar se o período de privação for demasiado longo.

Num caso extremo, é possível não se aprender língua alguma, haver uma total incompreensão da ideia de uma língua. $\mathrm{E}$ a linguagem, como nos alerta Church, não é apenas mais uma faculdade ou habilidade, é o que possibilita o pensamento, o que separa o pensamento do não pensamento, o que separa o humano do não humano. (Sacks, 1999, p. 73)

Isso está de acordo com as conclusões dos modelos de leitura para crianças ouvintes que enfatizam a importância de um adequado desenvolvimento linguístico precoce. Catts, Hogan e Adolf (2005), assim como Scarborough (2005), asseveram que é mais provável que as crianças tornem-se bons leitores quando apresentam uma forte fundação linguística. O que esses autores e outros (e.g., McGuinness, 2006; Viana, 2001) dizem no contexto da aquisição da linguagem por ouvintes é também pertinente para os surdos.

Assim, a aquisição tardia da Libras por nossos participantes pode ser uma das causas da falta de correlação encontrada entre a idade de aquisição dessa língua e o seu desempenho em leitura. Contrariamente ao que acontece com as crianças ouvintes com desenvolvimento adequado da linguagem oral, os membros da nossa amostra não puderam utilizar o equivalente dessa linguagem, no caso a Libras, como referência para a aprendizagem do português escrito.

Nesse contexto, os estudos com crianças surdas filhas de pais surdos, que dominam uma língua de sinais, são muito importantes. Stuckless e Birch (1997), por exemplo, encontraram que crianças surdas expostas a um ambiente linguístico desde o nascimento e que se apropriaram da língua de sinais de seus pais apresentaram melhor desempenho em leitura e escrita em comparação com aquelas filhas de pais ouvintes. Esses achados são confirmados por Hoffmeister (2000), Padden e Ramsey (2000), Chamberlain e Mayberry (2008) e Bélanger, Baum e Mayberry (2012), entre outros, ao mostrarem que a aprendizagem precoce da língua de sinais está diretamente relacionada ao bom desenvolvimento em leitura. Segundo Padden e Ramsey (2000), a exposição linguística à Língua de Sinais Americana (ASL) seria a responsável pelo desenvolvimento de habilidades que culminam na aprendizagem da leitura em inglês. Para as autoras, assim como as crianças ouvintes fazem associações de elementos sonoros com representações ortográficas, as crianças surdas fazem associações entre elementos da língua de sinais com a escrita. Tais associações não seriam descobertas fortuitas ou idiossincráticas de alguns indivíduos, mas resultantes da exposição sistemática a uma cultura de sinalizadores e de adultos surdos leitores, que direta ou indiretamente ensinam aos jovens sinalizadores como um texto escrito pode fazer sentido. Apesar de a leitura ser uma realização individual, é fundamentalmente uma realização cultural em que a sociedade e instituições se combinam para prover recursos para uma melhor alternativa para a leitura. 
No entanto, a despeito dos achados descritos, considerando que a leitura do surdo ocorre como aprendizagem de uma segunda língua, de forma geral a pergunta que se coloca é: "Mesmo em condições em que uma língua de sinais é adquirida desde o nascimento e de forma adequada, até que ponto ela pode facilitar o aprendizado da leitura, especialmente em escritas alfabéticas, por sua dependência na linguagem falada?"

A resposta a essa questão só pode ser dada por estudos longitudinais em que crianças surdas expostas à língua de sinais desde o nascimento sejam acompanhadas durante o processo de aprendizagem de uma língua alfabética. Não temos conhecimento de estudos que tenham testado essa questão longitudinalmente.

Sobre a nossa amostra, é importante destacar que todos os participantes são filhos de pais ouvintes, o que traz sérias implicações na aquisição da linguagem por esses sujeitos. $\mathrm{O}$ aprendizado da Libras se deu, como vimos, na maior parte em ambiente escolar, não tendo sido a língua adquirida de forma natural pelo surdo a partir da comunicação com familiares. O desconhecimento da Libras levou à adoção de uma comunicação caseira pelas famílias em $92 \%$ da amostra, prevalecendo a utilização de gestos, escrita, leitura labial e oralidade. Apesar de cumprir parcialmente um papel nos processos de desenvolvimento linguístico-cognitivos, esse tipo de comunicação é muito restrito, pois não permite, por exemplo, a comunicação de um sujeito surdo fora de seu círculo social mais próximo. Vale ressaltar que a língua é aquela que é partilhada por uma comunidade que ultrapassa as fronteiras da família (Nader, 2011). Além disso, como enfatizado por Pereira (2009), o domínio tardio de uma língua de sinais significa que, para muitas crianças, aprender a L1 e a ler e a escrever na L2 ocorre ao mesmo tempo.

\section{A INFLUÊNCIA DA INTELIGÊNCIA NÃO VERBAL}

\section{NA LEITURA DE SURDOS PROFUNDOS}

Finalmente, considerando a influência da inteligência não verbal na leitura de surdos profundos, constatamos níveis de baixo a mediano desempenho nas RPM por nossos participantes, com $41 \%$ da amostra apresentando percentil inferior a 25 , índice de baixo desempenho cognitivo, pelo menos para as crianças típicas. Tal resultado é preocupante especialmente mediante à correlação encontrada entre as RPM com o TCLS, que avalia compreensão e, por isso, requer processamento cognitivo superior, que faz uso de parte dos mecanismos avaliados pelas RPM, tais como a capacidade de abstração e de fazer inferências. Já o TCLP, que demanda processos básicos de leitura, não foi afetado significativamente pela fraca habilidade intelectual da amostra.

Um fato importante no presente estudo é que não houve diferença significativa entre o G1 e o G2 em habilidade cognitiva, mas sim em relação ao desempenho de leitura, com as crianças do G2 apresentando melhores resultados tanto em reconhecimento de palavras quanto na compreensão de sentenças. Considerando que a diferença principal entre os grupos se refere à utilização de meios alternativos de comunicação em combinação com a Libras, esse achado mostra que a utilização desses meios favorece o desempenho de leitura mesmo em participantes surdos com baixa habilidade cognitiva. 


\section{RECOMENDAÇÕES}

O presente trabalho tem implicações para a educação de crianças surdas nos seus lares desde o nascimento e também para a sua aprendizagem da leitura. Assim, nossa primeira recomendação diz respeito às famílias de surdos. Como apontado por Padden e Ramsey (2000), os surdos que tiveram melhores resultados na leitura usavam a ASL em diversos contextos, inclusive familiar. É importante que a família aprenda a Libras tão logo descubra a surdez da criança, para que a comunicação não seja interrompida. A segunda recomendação é que os pais tornem-se parceiros da escola na educação da criança surda, participando ativamente do seu processo educacional.

No que diz respeito à criança surda, a aquisição da Libras deve ocorrer tão logo se detecte o quadro de surdez. Essas crianças precisam ser postas em contato com pessoas fluentes na língua de sinais, sejam seus pais, professores ou outros. Sacks (1999) destaca que, assim que a comunicação por sinais for aprendida, tudo então pode decorrer: livre intercurso de pensamento, livre fluxo de informações, aprendizado da leitura e da escrita e, possivelmente, também da fala. Portanto, a terceira recomendação é que seja propiciado um ambiente linguístico que favoreça a aquisição natural da língua de sinais.

Concomitantemente à aprendizagem da Libras, recomendamos também que a criança surda seja estimulada a utilizar meios alternativos para comunicação, como a leitura labial e a oralização, que, além de lhe possibilitarem o estabelecimento de interações com os ouvintes, poderão the propiciar o desenvolvimento e familiaridade com a língua portuguesa. Tal aprendizado pode auxiliar no desenvolvimento de suas habilidades de leitura. Nesse sentido, sugerimos que seja iniciado o acompanhamento fonoaudiológico com profissionais especializados assim que possível. É importante salientar, entretanto, que alguns fonoaudiólogos ainda desconhecem a importância da língua de sinais para o desenvolvimento cognitivo da criança surda. Por esse motivo, nossa quarta recomendação é que os profissionais da fonoaudiologia se adéquem às especificidades linguísticas do sujeito surdo e trabalhem o ensino da fala com o apoio da Libras.

Assim que a criança surda aprender a ler, deve ser incentivado o hábito de leitura, de forma que possa construir suas hipóteses sobre a escrita da língua oral. Chamberlain e Mayberry (2008) reforçam a importância da frequência de leitura para promoção de leitores proficientes, destacando que esta é uma das características que difere leitores hábeis de leitores menos hábeis. Logo, a quinta recomendação é que a criança surda seja motivada a ler no ambiente familiar e educacional até mesmo em intensidade maior que crianças ouvintes.

A sexta e a sétima recomendações dizem respeito ao poder público, à necessidade de investimento em políticas voltadas especificamente para a educação de surdos. Essas recomendações nada mais são que a solicitação do cumprimento do que consta no decreto n. 5.626/2005. O artigo 14 desse decreto diz:

Art. 14. As instituições federais de ensino devem garantir, obrigatoriamente, às pessoas surdas acesso à comunicação, à informação e à educação nos processos seletivos, nas atividades e nos conteúdos curriculares desenvolvidos em todos 
os níveis, etapas e modalidades de educação, desde a educação infantil até à superior.

$\S 1^{\circ}$ Para garantir o atendimento educacional especializado e o acesso previsto no caput, as instituições federais de ensino devem:

I - promover cursos de formação de professores para:

a) o ensino e uso da Libras;

b) a tradução e interpretação de Libras - Língua Portuguesa; e

c) o ensino da Língua Portuguesa, como segunda língua para pessoas surdas;

II - ofertar, obrigatoriamente, desde a educação infantil, o ensino da Libras e também da Língua Portuguesa, como segunda língua para alunos surdos;

A sexta recomendação se refere ao ensino da Libras na educação infantil, o que não tem sido feito. Não existem projetos nem propostas políticas com esse objetivo. A comunidade surda tem se levantado em movimentos políticos reivindicando o cumprimento do referido decreto na íntegra, inclusive com a participação dos surdos no processo de educação das crianças surdas. Vários surdos já se formaram e outros estão se formando em cursos como pedagogia e letras, com o objetivo de atuarem no ensino da Libras nas escolas, mas não existe uma política de inclusão desses sujeitos na docência. Recomendamos o ensino da Libras às crianças surdas na educação infantil, dando prioridade a professores surdos, para que esses possam ser tanto modelos de língua quanto de identidade para as crianças.

A sétima recomendação, é que seja elaborada uma política de formação de professores de português como L2 para surdos. Já não há mais espaço para improvisos, adaptações, tentativas com acertos e muitos erros. Os professores precisam de uma formação acadêmica adequada. Os resultados de pesquisas acadêmicas precisam ser levados em consideração, e a prática deve ser trazida para a universidade, para ser avaliada e mais bem trabalhada pelos próprios professores.

\section{CONCLUSÃO}

Após investigação sobre o desempenho de leitura por surdos, conclui-se que, em virtude das barreiras encontradas por esses indivíduos para o seu desenvolvimento linguístico, é de se esperar que apresentem atrasos em seu processo de escolarização, afetando diretamente sua vida familiar, escolar e social.

Baixos desempenhos em avaliação cognitiva, defasagem escolar e baixos índices de leitura, quando comparados à população ouvinte, não podem ser considerados inerentes à surdez, mas sim decorrentes da fraca exposição linguística, vivenciada por muitos surdos. A exposição tardia a uma língua à qual se tenha pleno acesso, como a língua de sinais, causa inúmeros prejuízos, principalmente aos surdos que têm pais ouvintes, que só adquirem essa língua após entrarem na escola. 
Apenas cerca de 5\% dos surdos possuem pais surdos e têm contato com a língua de sinais desde o nascimento. Os fatores que envolvem a condição do surdo filho de pais ouvintes - aquisição tardia de linguagem, despreparo e falta de participação da maioria dos familiares na educação, falta de uma política de educação que priorize a aquisição da Libras o mais cedo possível, falta de investimento público na formação de professores especializados, falta de um ambiente adequado que estimule o letramento desde os primeiros anos de vida — por si só já o colocam em condições desiguais de aprendizagem em relação ao ouvinte, pois, além de aprender a Libras, ele deve aprender o português como L2, o que não acontece nas escolas inclusivas, principalmente, já que essa disciplina é ministrada na maioria das vezes em classes mistas, nas quais alunos surdos aprendem com outros alunos ouvintes.

O atual cenário de ensino da leitura para a população surda carece de intervenções para que seus membros tornem-se leitores hábeis e possam participar ativamente da cultura majoritária de seu país, mediada pela língua portuguesa, que é a principal ponte para o mundo dos ouvintes. Sendo a oralização e a leitura labial agentes facilitadores no processo de ensino/aprendizagem dos surdos, sugerimos que se invista nesses meios de comunicação alternativos, que, em complemento à língua de sinais, possam propiciar maior exposição do sujeito surdo à língua portuguesa, levando a um melhor desempenho em leitura.

\section{REFERÊNCIAS}

Alegría, J.; Dejean, K.; Capouilez, J. M.; Leybaert, J. Role played by cued speech in the identification of written words encountered for the first time by deaf children: a preliminary. Cued Speech Journal, Washington, DC: National Cued Speech Association, v. IV, p. 4-9, 1990.

Bélanger, N. N.; Baum, S. R.; Mayberry, R. I. Reading difficulties in adult deaf readers of French: phonological codes, not guilty! Scientific Studies of Reading, United Kingdom: Tayloe \& Francis, v. 16, n. 3, p. 263-285, 2012.

Blennerhassett, L.; Strohmeier, S. J.; Нibbett, C. Criterion-related validity of Raven's Progressive Matrices with Deaf Residential School students. American Annals of the Deaf, Washington: Gallaudet University Press, v. 139, n. 2, p. 104-110, 1994.

Botelho, P. Linguagem e letramento na educação dos surdos: ideologias e práticas pedagógicas. Belo Horizonte: Autêntica, 2010.

Brasil. Lei n. 10. 436, de 24 de abril de 2002. Dispõe sobre a Língua Brasileira de Sinais - LIBRAS. Diário Oficial da União, Brasília, DF, 25 abr. 2002.

. Decreto n. 5.626, de 22 de dezembro de 2005. Regulamenta a lei n. 10.436, de 24 de abril de 2002, que dispõe sobre a Língua Brasileira de Sinais — Libras, e o art. 18 da lei n. 10.098, de 19 de dezembro de 2000. Diário Oficial da União, Brasília, DF, 23 dez.2005.Disponível em: <http://www.planalto.gov.br/ccivil_03/_ato2004-2006/2005/ decreto/d5626.htm>. Acesso em: 10 jan. 2014.

. Secretaria Municipal de Educação. Diretoria de Orientação Técnica. Projeto Toda Força ao Primeiro Ano: Contemplando as especificidades dos alunos surdos. São Paulo: SME/DOT, 2007. 
. Política Nacional de Educação Especial na Perspectiva da Educação Inclusiva. Brasília: MEC/SEESP,2008. Disponível em: <http://portal.mec.gov.br/seesp/arquivos/ pdf/politica.pdf $>$. Acesso em: 10 jan. 2014.

Capovilla, F. C.; Capovilla, A. G. S. Educação da criança surda: o bilinguismo e o desafio da descontinuidade entre a Língua de Sinais e a escrita alfabética. Revista Brasileira de Educação Especial, Marília: ABPEE, v. 8, n. 2, p. 127-156, 2002.

Capovilla, F. C.; Viggiano, K. Q.; Capovilla, A. G. S.; Raphael, W. D.; Bidá, M. C. P. R.; Neves, M. V.; Mauricio, A. C. Como avaliar o desenvolvimento da competência de leitura silenciosa de palavras em surdos do ensino fundamental ao médio, e analisar processos de reconhecimento e decodificação: versão original do Teste de Competência de Leitura de Palavras. In: Capovilla, F. C.; Raphael, W. D. (Orgs.). Enciclopédia da Lingua de Sinais Brasileira: o mundo do surdo em Libras, Vol. 1: Sinais da Libras e o universo da educação; e como avaliar o desenvolvimento da competência de leitura de palavras (processos de reconhecimento e decodificação) em escolares surdos do Ensino Fundamental ao Médio. São Paulo: Editora da Universidade de São Paulo, Imprensa Oficial do Estado de São Paulo, Vitae, CAPES, CNPq, FAPESP, 2004.

Capovilla, F. C.; Viggiano, K. Q.; Capovilla, A. G. S.; Raphael, W. D.; Bidá, M. C. P. R.; Neves, M. V.; Mauricio, A. C. Como avaliar o desenvolvimento da compreensão de leitura de sentenças em surdos do Ensino Fundamental ao Médio, e analisar processamento sintático para extração de significado: Versão original validada e normatizada do Teste de Competência de Leitura de Sentenças (TCLS1.1). In: Capovilla, F. C.; Raphael, W. D. (Orgs.). Enciclopédia da Lingua de Sinais Brasileira: o mundo do surdo em Libras, Vol. 3: Sinais da Libras e o universo da família, relações familiares, e casa; e como avaliar o desenvolvimento da compreensão de leitura de sentenças em surdos do ensino fundamental ao médio. São Paulo: EDUSP, Imprensa Oficial do Estado de São Paulo, 2005.

Capovilla, F. C.; Sousa-Sousa, C. C.; Maki, K.; Ameni, R.; Neves, M. V. Avaliando a habilidade de leitura orofacial em surdos do ensino fundamental e comparando a eficácia relativa de modelos de legibilidade orofacial fonético-articulatório e de Dória.In: Sennyey, A. L.; Capovilla, F. C.; Montiel, J.M. (Orgs.). Transtornos de aprendizagem: da avaliação à reabilitação. São Paulo, SP: Artes Médicas, 2008. p. 207-220.

Catts, H. W.; Hogan, T. P.; Adolf, S. M. Developmental changes in reading and reading disabilities. In: CatTs, H.; Kamhi, A. (Eds.). Connections between language and reading disabilities. Mahwah, NJ: Erlbaum, 2005. p. 25-40.

Chamberlain, C.; Mayberry, R. American Sign Language syntactic and narrative comprehension in skilled and less skilled readers: Bilingual and bimodal evidence for the linguistic basis of reading. Applied Psycholinguistics, Cambridge: Cambridge University Press, n. 29, p. 367-388, 2008.

Connett, R. O.; Daisey, M. E. The cued speech resource book for parents of deaf children. Raleigh, North Carolina: National Cued Speech Association, 1992.

Dell'Aringa, A. H. B.; Adachi, E. S.; Dell'Aringa, A. R. A importância da leitura orofacial no processo de adaptação de AASI. Revista Brasileira de Otorrinolaringologia, São Paulo: ABORL, v. 73, n. 1, p. 101-105, 2007. 
Eco, U. O conceito de texto. São Paulo: EDUSP, 1984.

EHRI, L. C. Development of sight word reading: phases and findings. In: SNowling, M. J.; Hulme, C. (Eds.). The science of reading: a handbook. Oxford: Blackwell Publishing, 2010. p. 362-378.

Fernandes, E. (Org.). Surdez e bilinguismo. Porto Alegre: Mediação, 2011.

Ferreira-Brito, L. et al. Educação especial: língua brasileira de sinais. Brasília, DF: MEC/SEESP, 1997. (Série Atualidades Pedagógicas, 4).

Hoaglin, D. C.; Iglewicz, B. Fine tuning some resistant rules for outlier labeling. Jornal of American Statistical Association, Boston: ASA, n. 82, p. 1.147-1.149, 1987.

Hoffmeister, R. J. A piece of the puzzle: ASL and reading comprehension in deaf children. In: Chamberlain, C.; Morford, J. P.; Mayberry, R. (Eds.). Language acquisition by eye. Mahwah, NJ: Lawrence Erlbaum and Associates, 2000. p. 143-163. IBM SPSS statistics 21. [S.1.]: IBM, 2012. Software. Disponível em: <https://www.

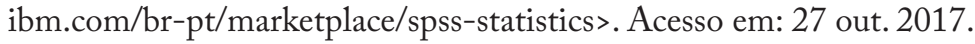

Kato, M. O aprendizado da leitura. 4. ed. São Paulo: Martins Fontes, 1995.

LACERDA, C. B. F.Um pouco da história das diferentes abordagens na educação dos surdos. Cadernos CEDES, Campinas: UNICAMP [online],v. 19, n. 46,p.68-80,1998. Disponível em: <http://dx.doi.org/10.1590/S0101-32621998000300007>. Acesso em: 23 set. 2013. Leybaert, J. Learning to read with a hearing impairment. In: Snowling, M. J. The science of reading: a handbook. Oxford: Blackwell Publishing, 2005. p. 379-396.

Lindner, L. B. O feto como ser ouvinte. Texto (Monografia) - Centro de Especialização em Fonoaudiologia Clínica, Porto Alegre, 1999.

Martin, W. E.; Bridgmon, K. D. Quantitative and statistical research methods: from Hypothesis to Results. New Jersey: Wiley, 2012.

Masutti, M. L. Políticas linguísticas: o português como a segunda língua dos surdos. In: Moura, M. C.; Campos, S. R. L.; Vergamini, S. A. A. Educação para surdos: práticas e perspectivas II. São Paulo: Santos, 2011. p. 49-63.

Mayberry, R. I.; Giudice, A. A.; Lieberman, A. M. Reading achievement in relation to phonological coding and awareness in deaf readers: a meta-analysis. Journal of Deaf Studies and Deaf Education, United Kingdom: Oxford University Press, v. 16, n. 2, p. 164-188, 2010.

McGuinness, D. O ensino da leitura: o que a ciência nos diz sobre como ensinar a ler. Tradução de Luzia Araújo. Porto Alegre: Artmed, 2006.

Morais, J. A arte de ler. Tradução de Álvaro Lorencini. São Paulo: UNESP, 1996.

Morton, J. An information-processing account of reading acquisition. In: GalabURda, A. M. From reading to neurons. Cambridge: The MIT Press, 1989.

Moura, M. C.; Campos, S. R. L.; Vergamini, S. A. A. Educação para surdos: práticas e perspectivas II. São Paulo: Santos, 2011.

Nader, J. M. V. Aquisição tardia de uma língua e seus efeitos sobre o desenvolvimento cognitivo dos surdos. Dissertação (Mestrado em Linguística) - Universidade Estadual de Campinas, Campinas, 2011. 
Neves, M. V. O.; Alarcão, F. S. P. Perfil neuropsicológico do adolescente surdo: um estudo utilizando os Testes das Matrizes Progressivas Escala Geral - C. J. Raven e WISC-III. Revista Espaço Cientifico Livre, [S.1: s.n.], v. 2, n. 8, p. 9-24, 2012.

Padden, C.; Ramsey, C. American sign language and reading ability in deaf children. In: Chamberlaine, C.; Morford, J. P.; Mayberry, R. I. (Eds.). Language acquisition by eye. New Jersey: Lawrence Erlbaum Associates, 2000. p. 165-190.

Pereira, M. C. Leitura, escrita e surdez. 2. ed. São Paulo: FDE, 2009.

Quadros, R. M. Aquisição de L1 E L2: o contexto da pessoa surda. In: SeminÁrio Desafios e Possibilidades na Educação Bilíngue para Surdos, 1994, Porto Alegre. Anais... Porto Alegre, 1997a.

1997b.

. Educação de surdos: a aquisição da linguagem. Porto Alegre: Artes Médicas,

Raven, J. Teste das matrizes progressivas escala geral: manual. Rio de Janeiro: Centro Editor de Psicologia Aplicada, 2008.

. Spearman on intelligence. Web Psych Empiricist, [S.1.: s.n.], 2011. Disponível em: <http://wpe.info/vault/raven11a/raven11a.pdf>. Acesso em: 26 out. 2017.

SAcks, O. Vendo vozes: uma jornada pelo mundo dos surdos. Tradução de Alfredo Barcellos Pinheiro de Lemos. Rio de Janeiro: Imago, 1999.

Scarborough, H. S. Developmental relationships between language and reading: econciling a beautiful hypothesis with some ugly facts. In: Catte, H. W. (Ed.). The connection between language and reading disabilities. Mahwah, NJ: LEA, 2005. p.3-22. Share, D. L. Phonological recoding and self-teaching: sine qua non of reading acquisition. Cognition, Netherlands: Hague, Mouton, n. 55, p. 151-218, 1995.

Silva, A. B. P.; Pereira, M. C. C. O aluno surdo na escola regular: imagem e ação do professor. Psicologia: teoria e pesquisa, Brasília:UnB, v. 19, n.2, p. 173-176, 2003. Disponível em: <http://www.scielo.br/pdf/ptp/v19n2/a10v19n2.pdf >. Acesso em: 17 jun. 2012.

Silva, S. G. L. Pedagogia surda e ensino da língua portuguesa para surdos. In: Perlin, G.; Stumpf, M. (Orgs.). Um olhar sobre nós surdos: leituras contemporâneas. Curitiba: CRV, 2012. p. 265-274.

Soares, M. Letramento: um tema em três gêneros. Belo Horizonte: Autêntica, 2002.

Stuckless, R., Birch, J. The influence of early manual communication on the linguistic development of deaf children. American Annals of the Deaf, Washington: Gallaudet University Press n. 142, p. 71-79, 1997.

Svartholm, K. O bilinguismo sob o ponto de vista de Kristina Svartholm - Suécia. In: Moura, M. C.; Campos, S. R. L.; Vergamini, S. A. A. (Orgs.). Educação para surdos: práticas e perspectivas II. São Paulo: Santos, 2011. p. 147-155.

Tukey, J. W. Exploratory data analysis. Reading, MA: Addison-Wesley, 1977.

Viana, F. L. P. Melhor falar para melhor ler. 2. ed. Portugal: Universidade do Minho, 2001. (Coleção Infas).

WILcox, R. R. Fundamentals of modern statistical methods: substantially improving power and accuracy. New York: Springer, 2010. 
Wiтковкі, S. A. Surdez e preconceito: a norma da fala e o mito da leitura da palavra falada. Revista Brasileira de Educação, Rio de Janeiro: ANPEd; Campinas: Autores Associados, v. 14, n. 42, p. 565-606, set./dez. 2009.

\section{SOBRE OS AUTORES}

Andreia Chagas Rocha Toffolo é mestre em psicologia pela Universidade Federal de Minas Gerais (UFMG). Professora da Universidade Federal de Ouro Preto (UFOP).

E-mail: deiachagasrocha@gmail.com

Douglas de Araújo Vilhena é doutorando em neuropsicologia pela Universidade Federal de Minas Gerais (UFMG).

E-mail: douglasvilhena@gmail.com

Elidéa Lúcia Almeida Bernardino é doutora em linguística aplicada pela Boston University (Estados Unidos). Professora da Universidade Federal de Minas Gerais (UFMG).

E-mail: elideabernardino@gmail.com

Ângela Maria Vieira Pinheiro é doutora em psicologia cognitiva pela University of Dundee (Escócia). Professora da Universidade Federal de Minas Gerais (UFMG).

E-mail: pinheiroamva@gmail.com

Recebido em $1^{\circ}$ de abril de 2015

Aprovado em 3 de março de 2016 